\title{
Molecular modeling of organic redox-active battery materials
}

\author{
Fornari, Rocco Peter; de Silva, Piotr
}

Published in:

Wiley Interdisciplinary Reviews: Computational Molecular Science

Link to article, DOI:

10.1002/wcms.1495

Publication date:

2021

Document Version

Peer reviewed version

Link back to DTU Orbit

\section{Citation (APA):}

Fornari, R. P., \& de Silva, P. (2021). Molecular modeling of organic redox-active battery materials. Wiley Interdisciplinary Reviews: Computational Molecular Science, 11(2), [e1495]. https://doi.org/10.1002/wcms.1495

\section{General rights}

Copyright and moral rights for the publications made accessible in the public portal are retained by the authors and/or other copyright owners and it is a condition of accessing publications that users recognise and abide by the legal requirements associated with these rights.

- Users may download and print one copy of any publication from the public portal for the purpose of private study or research.

- You may not further distribute the material or use it for any profit-making activity or commercial gain

- You may freely distribute the URL identifying the publication in the public portal

If you believe that this document breaches copyright please contact us providing details, and we will remove access to the work immediately and investigate your claim 


\title{
Molecular modelling of organic redox-active battery materials
}

\author{
First author \\ Rocco Peter Fornari \\ Department of Energy Conversion and Storage \\ Technical University of Denmark \\ Anker Engelunds Vej 301, 2800 Kongens Lyngby, Denmark \\ e-mail: rocfor@dtu.dk \\ ORCID: 0000-0002-3792-8262 \\ Second author \\ Piotr de Silva* \\ Department of Energy Conversion and Storage \\ Technical University of Denmark \\ Anker Engelunds Vej 301, 2800 Kongens Lyngby, Denmark \\ e-mail: pdes@dtu.dk \\ ORCID: 0000-0002-4985-7350
}

\begin{abstract}
Organic redox-active battery materials are an emerging alternative to their inorganic counterparts currently used in the commercialized battery technologies. The main advantages of organic batteries are the potential for low-cost manufacturing, tunability of electrochemical properties through molecular engineering, and their environmental sustainability. The search for organic electroactive materials that could be used for energy storage in mobile and stationary applications is an active area of research. Computer simulations are used extensively to improve the understanding of the fundamental processes in the existing materials and to accelerate the discovery of new materials with improved performance. We will focus on two main types of redox-active organic battery materials, i.e. solid-state organic electrode materials and organic electrolytes for redox flow batteries. Because organic materials are made of molecular building blocks, the molecular modelling methodology is usually the most appropriate to investigate their properties at the electronic and atomistic scales. After introducing the fundamentals of computational organic electrochemistry, we will survey its most recent applications in organic battery research and outline some of the remaining challenges for the development and applications of atomic-scale modelling techniques in the organic battery context.
\end{abstract}

Graphical/Visual Abstract and Caption 

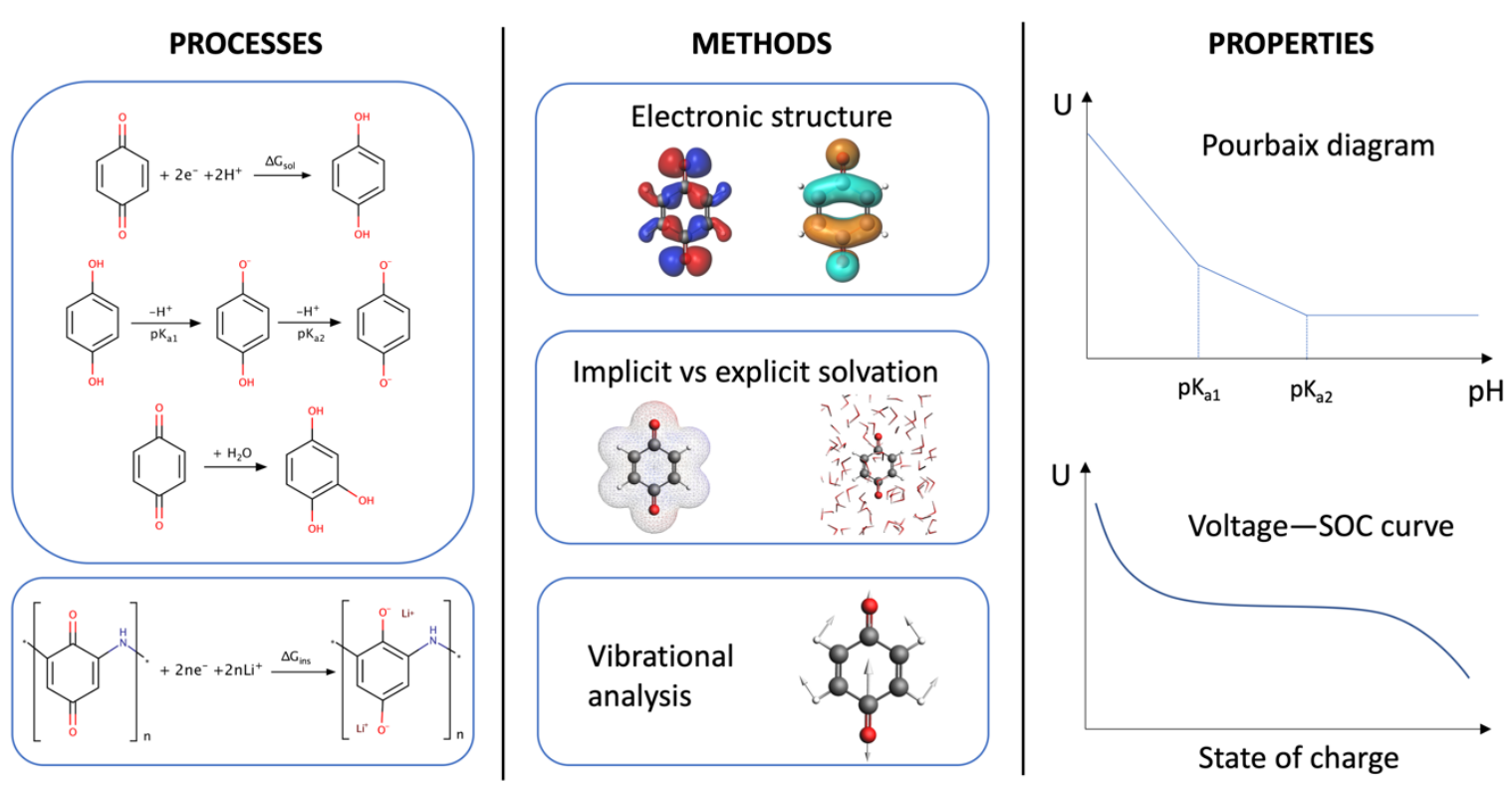

Computational chemistry offers a set of tools for atomic-scale simulations of electrochemical properties of organic redox-active materials. Molecular modelling is used in the development of next-generation organic battery materials for mobile and stationary applications.

\section{INTRODUCTION}

Currently, we are witnessing a rapidly growing demand for various electrochemical energy storage solutions. This trend is sustained by the ever-increasing global population with its energy-hungry lifestyle and the accompanying environmental concerns. The need for on-demand power supply is propelled by the three main application areas: electromobility, portable devices, and stationary energy storage. Each of these application areas has different requirements in terms of energy and power densities, long-term stability, and acceptable price levels. At present, the lithium-ion technology appears as the most versatile for rechargeable batteries.(1-5) The basic idea is to shuttle Li cations between two intercalation materials, typically graphite as the anode and a transition metal oxide as the cathode. In recent years, lithium-ion batteries (LIBs) have led to the proliferation of powerful electronic devices like smartphones and tablets as well as enabled electric vehicles with reasonable driving ranges. LIBs are also used in stationary applications for storing the excess energy from renewable but intermittent power sources like solar cells or wind turbines. Another promising technology for stationary energy storage is the redox flow battery (RFB). $(6,7)$ The vanadium $\operatorname{RFB}(8)$ is the most developed technology which has been already commercialized. In RFBs the electroactive material is dissolved in a liquid and pumped through an electrochemical cell during the chargedischarge cycles. Such a design allows to decouple the capacity (determined by the volume of the storage tanks) and power (determined by the electrode surface area); therefore, it is particularly attractive for large-scale applications. Despite remarkable progress in these technologies, the commercialized batteries are typically based on redox-active materials that contain transition metals (e.g. Co or V) which can be expensive, toxic, scarce, unethically mined, and sourced in politically unstable regions. In light of these disadvantages, there is increasing attention placed on organic redox-active materials as the more sustainable alternatives. Compared to their inorganic counterparts, organic materials are lightweight, flexible, made of abundant elements, and environmentally benign. Due to the enormous size of the chemical space, they have tuneable 
properties and potential for low manufacturing costs. For these reasons, the development of new solid-state organic electrode materials (OEMs)(9-16) for traditional encapsulated batteries as well as soluble organic materials for RFB electrolytes(17-21) is an active and trending area of research.

The rate of the discovery of new functional materials depends on how efficiently we can come up with new ideas and then test them for specific applications. Both tasks can be greatly facilitated by computational modelling of relevant materials and processes. Simulations of fundamental physical and chemical processes in known materials lead to a better understanding of their properties and allows to formulate new design strategies for materials with improved performance. At the same time, simulations are used to predict properties of yet inexistent materials and screen them for their potential applications. Both types of simulations are the basis for computational molecular design, which has become an essential component of the accelerated discovery of organic battery materials. The success of this approach critically relies on the accuracy and efficiency of available computational methods and the reliable modelling of organic redox-active materials poses several challenges. As the underlying process for electrochemical energy storage is a redox reaction involving the exchange of electrons, electronic structure calculations are essential for the prediction of relevant properties. Both thermodynamics and kinetics of redox reactions are critical for the battery performance as they determine the amount of the stored energy and the available power, respectively. The condensed-phase environment of the reactants and products affects the energetics of the reaction but also determines the charge and mass transport phenomena in the battery. Therefore, capturing the bulk effects of the solvent in RFBs and the solid material in organic electrodes is essential for electronic structure and atomistic simulations. Finally, many critical electrochemical phenomena happen at the interface between a solid-state electrode and a liquid electrolyte, so modelling of such interfaces is another important aspect of simulations. In the following, we will give an overview of the state of the art in atomic-scale modelling of organic redoxactive battery materials. After introducing the background theory and methodology for computational organic electrochemistry, we will review specific applications in simulations of organic materials for RFBs and solid-state electrodes. Finally, we will give our perspective on the outstanding challenges and future directions in atomic-scale modelling of organic battery materials.

\section{COMPUTATIONAL ORGANIC ELECTROCHEMISTRY}

In this section, we will briefly outline some of the computational methods dealing with aspects of organic materials relevant to electrochemical energy storage. These aspects include thermodynamics of electrochemical reactions, protonation state, solubility and stability. The basic concepts behind the modelling of organic redox-active materials are illustrated in Figure 1.

Electrochemical reactions are in general electron transfer processes involving an electroactive material which undergoes reduction/oxidation (redox). Organic redox-active compounds can be molecules in solution or solid materials such as polymers, glasses, and crystals. In this section, we will start by outlining the procedure to compute the perhaps most important property of an electroactive material, the standard reduction potential. Next, we will briefly discuss the calculation of the acidity constant $\mathrm{pK}_{\mathrm{a}}$ which determines the protonation state at a given $\mathrm{pH}$ and the voltage of solid-state intercalation electrodes. This will be followed by a general discussion about the stability of redox-active compounds. 


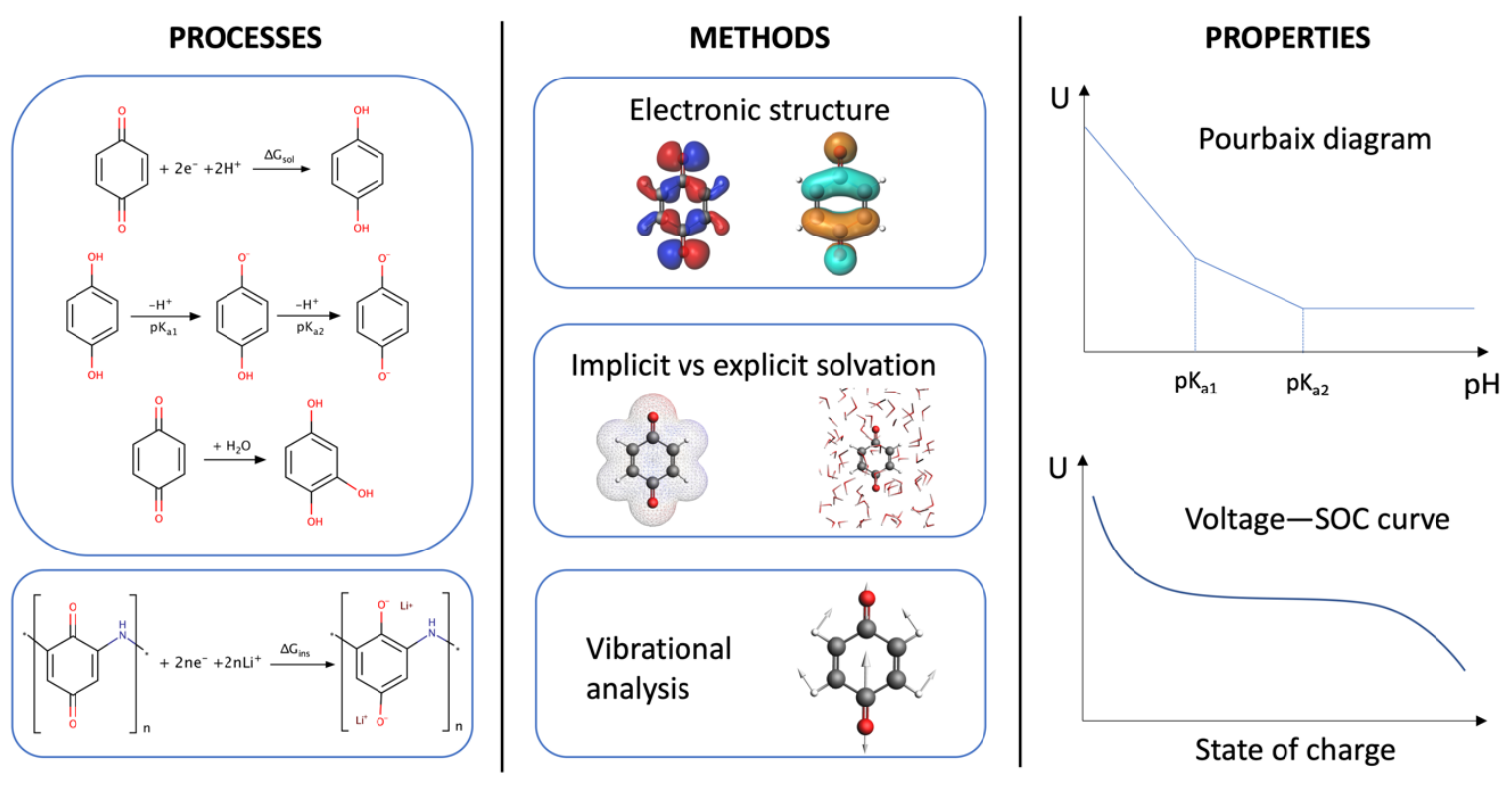

Figure 1. Left panel: Quinone-based examples of (electro-)chemical processes in organic redox-active materials for aqueous RFBs (top) and solid-sate OEMs (bottom); Middle panel: Basic methods used in computational electrochemistry of organic materials; Right panel: Examples of electrochemical properties that can be simulated with the discussed methodology.

The standard reduction potential $U^{0}$ of the reaction $\mathrm{Ox}+e^{-} \rightarrow$ Red is defined for the oxidized (Ox) and reduced (Red) forms (charge not specified) at standard conditions, i.e. when their activities are 1. Experimentally, $U^{0}$ is obtained by extrapolation first to infinite dilution (zero ionic strength), and then to standard concentration $1 \mathrm{M}$ (or pressure $1 \mathrm{~atm}$ ).(22)

$$
U^{0}=\frac{1}{n F} \Delta G_{\text {sol }}^{0}-U_{\text {SHE }}
$$

It is directly proportional to the standard free energy of reduction $\Delta G_{\text {sol }}^{0}$ computed in the environment of the compound (from now on referred to as solution) and referenced against the potential of a standard electrochemical reaction such as the standard hydrogen electrode (SHE) or an internal reference, i.e. a well-known redox couple computed at the same level of theory.(23) $n$ is the number of electrons transferred and $F$ is the Faraday constant. $\Delta G_{\text {sol }}^{0}=\Delta E_{\text {sol }}+\Delta G_{\text {corr }}$, where $\Delta E_{\mathrm{sol}}=E_{\mathrm{sol}}(\mathrm{Red})-E_{\mathrm{sol}}(\mathrm{Ox})$ can be obtained directly(24) as the difference between the electronic energies of the reduced and oxidised forms of the compound, both in solution. $\Delta G_{\text {corr }}$ is the difference between the thermal corrections of each form (see below). For computing $\Delta E_{\text {sol }}$ and $\Delta G_{\text {corr }}$, any quantum mechanical (QM) electronic structure method is in principle appropriate, but density functional theory (DFT) offers the best accuracy at a reasonable cost. The cheapest and simplest way to consider the environment's effects is using implicit solvation models $(25,26)$ (e.g. PCM,(27) C-PCM, $(28,29)$ COSMO,(30) SMD(31)) which are implemented in all main quantum chemistry codes. These models mimic the electrostatic response of the solvent medium to the solute's electronic density with a polarizable continuum. On the surface of a cavity containing the solute, a large number of point charges represent the continuum. The mutual interaction between these charges and the electronic density of the solute is included in the self-consistent field calculation and $E_{\mathrm{sol}}$ is obtained. The thermal correction $G_{\mathrm{corr}}$, which includes the zero-point vibrational energy as well as vibrational enthalpy and entropic contributions to the free energy, is readily obtained by performing a vibrational frequency calculation with any popular QM program. It 
is still a matter of debate whether the frequencies computed within an implicit solvation model are accurate, $(24,32)$ therefore it may be a more robust choice to compute them in the gas phase.

The reduction potential $U$ under non-standard conditions depends on the activities or effective concentrations $a_{\mathrm{Red}}$ and $a_{\mathrm{Ox}}$ of the redox species, which may differ from unity. The Nernst equation describes this deviation from the standard potential(22):

$$
U=U^{0}-\frac{R T}{n F} \ln \left(\frac{a_{\mathrm{Red}}}{a_{0 \mathrm{x}}}\right)
$$

where $R$ is the gas constant and $T$ is the temperature in $\mathrm{K}$. The non-unitary activities account for the ionic strength and for chemical effects such as side reactions, ion pairing, complexation and protonation.(22) In aqueous solutions, the protonation state of the reactants and products of a redox reaction depends on the $\mathrm{pH}$. Therefore, to properly define the electrochemical reaction at given conditions, one has to know the acidity constants of the solutes. For computing the $\mathrm{pK}_{\mathrm{a}}$, similar calculations as for the reduction potential are required:

$$
\mathrm{pK}_{\mathrm{a}}=\frac{\Delta G_{\text {sol }}^{0}}{R T \ln (10)}
$$

where $\Delta G_{\text {sol }}^{0}=\Delta E_{\text {sol }}+\Delta G_{\text {corr }}+\Delta G_{\text {sol }}^{0}\left(\mathrm{H}^{+}\right)$is the free energy of the deprotonation reaction $\mathrm{AH} \rightarrow \mathrm{A}^{-}+\mathrm{H}^{+} . \Delta G_{\mathrm{s}}^{0}\left(\mathrm{H}^{+}\right)$is the solvation free energy of one proton (care should be taken to use a value consistent with that of $\left.U_{\mathrm{SHE}}\right)(22,33)$ and the other terms are equivalent to those entering eq. (1). $R$ is the gas constant and $T$ is the temperature in $\mathrm{K}$.

A general proton-coupled electron transfer reaction can be written as $0 \mathrm{xH}_{x}+n_{\mathrm{p}} \mathrm{H}^{+}+n_{\mathrm{e}} \mathrm{e}^{-} \rightarrow$ $\operatorname{RedH}_{x+n_{p}}$, where $n_{e}$ and $n_{p}$ are the number of electrons and protons transferred. $n_{\mathrm{p}} \Delta G_{\mathrm{s}}^{0}\left(\mathrm{H}^{+}\right)$ needs to be added to the $\Delta G_{\text {sol }}^{0}$ term in eq. (1). The Nernst equation (2) becomes dependent on the $\mathrm{pH}$ of the solution and on the $\mathrm{pK}_{\mathrm{a}}$ values of $\mathrm{OxH}=\mathrm{OxH}_{x}$ and $\mathrm{RedH}=\mathrm{RedH}_{x+n_{p}}$ (number of hydrogens not specified for simplicity) and is often expressed in the following form at $T=298 \mathrm{~K}$ :

$$
U=U^{0}+0.059 \frac{n_{p}}{n_{e}}\left[\log \left(\frac{a_{\mathrm{OxH}}}{a_{\mathrm{RedH}}}\right)-\mathrm{pH}\right]
$$

where $\mathrm{pH}=-\log \left(a_{\mathrm{H}^{+}}\right)$and $a_{\mathrm{AH}}=a_{\mathrm{A}} 10^{\mathrm{pK}_{\mathrm{a}}(\mathrm{AH})-\mathrm{pH}}$ with $\mathrm{A}$ being $\mathrm{Ox}$ or Red. A plot of $U$ as a function of the $\mathrm{pH}$ can be used to construct a Pourbaix diagram such as the one sketched in the top right panel of Figure 1 for a typical quinone. $\mathrm{pK}_{\mathrm{a} 1}$ and $\mathrm{pK}_{\mathrm{a} 2}$ concern the first and second protonation reactions of the reduced species $\mathrm{Red}^{2-}+\mathrm{H}^{+} \rightarrow \mathrm{RedH}^{-}$and $\mathrm{RedH}^{-}+\mathrm{H}^{+} \rightarrow \mathrm{RedH}_{2}$, while Ox is not protonated in the range of $\mathrm{pH}$ considered (the $\mathrm{pK}_{\mathrm{a}} \mathrm{S}$ of $\mathrm{OxH}^{+}$and $\mathrm{OxH}^{2+}$ are thought to be $\leq-7$ for benzoquinone(34)). When $\mathrm{pH}<\mathrm{pK}_{\mathrm{a} 1}$, the slope of the $U \mathrm{vs} \mathrm{pH}$ curve is $0.059 \mathrm{~V} / \mathrm{pH}$ indicating a $2 \mathrm{e}^{-} / 2 \mathrm{H}^{+}$reaction. When $\mathrm{pK}_{\mathrm{a} 1}<\mathrm{pH}<\mathrm{pK}_{\mathrm{a} 2}$, the slope is $0.0295 \mathrm{~V} / \mathrm{pH}$ since the reaction is $2 \mathrm{e}^{-} / 1 \mathrm{H}^{+}$, and finally at $\mathrm{pH}>\mathrm{pK}_{\mathrm{a} 2} U$ becomes independent of the $\mathrm{pH}$ since the protons and the protonated forms do not participate in the $2 \mathrm{e}^{-}$reaction. When all protonation and redox processes are known, the Pourbaix diagram serves as a map of the species stable at any given combination of $U$ and $\mathrm{pH}$.

Standard DFT methods such as B3LYP used in combination with implicit solvation usually yield reasonably accurate reduction potentials. $(35,36)$ One commonly adopted way to improve the 
accuracy of $\Delta G_{\text {sol }}^{0}$ is to use a thermodynamic cycle, i.e. compute single point gas-phase energies at a higher level of theory and add the resulting high-level correction $\Delta E_{\text {gas }}^{\mathrm{H}}-\Delta E_{\text {gas }}^{\mathrm{L}}$ (where $\mathrm{H}$ and $\mathrm{L}$ denote the high and low level of theory) to the $\Delta G_{\text {sol }}^{0}$ computed at the lower level. $(22,24,37,38)$ However, even when improving the gas-phase energy difference, the accuracy still depends on that of the solvation free energies,(39) and the use of a thermodynamic cycle does not necessarily improve accuracy compared to the direct method.(24) Implicit solvation models have evolved and improved in recent years and can now efficiently describe solvation effects in a broad range of systems including electrode-liquid interfaces and periodic systems.(40) Implicit solvation models are likely to give larger errors for the solvation free energies in some specific situations, e.g. when the solute has a large charge and/or there are specific solute-solvent interactions such as water molecules or ions coordinating a moiety of the molecule.(40) When this is the case, explicit modelling of the solvent can improve the accuracy considerably.(41) In mixed explicit/implicit (or cluster-continuum) solvation models, some of the solvent molecules are treated explicitly at the same level of theory of the solute (explicit QM solvent).(42-45) The cluster of solute and solvent is then embedded in a polarizable continuum which models the long-range electrostatics with acceptable accuracy. Cluster-continuum models lead to significant improvement in the accuracy of solvation free energies and pKa values with respected to pure continuum models.(45) In fully explicit solvation models,(46-48) the solvent outside the QM region is described explicitly by a molecular mechanics (MM) classical force field, which can optionally include an approximate treatment of polarization effects. Both in mixed and fully explicit models, a single configuration of the solvent molecules is not always meaningful: it may be necessary to produce a sample of many configurations and perform thermodynamic integration to compute the solvation free energy. $(22,46)$ In both mixed and explicit solvation models, the number of solvent molecules which need to be included in the QM region to achieve the desired accuracy needs to be determined on a case-by-case basis. In a recent example, a method including machine learning has been proposed to compare microsolvation structures.(49)

In solid-state intercalation electrodes, the redox reaction of the active material is coupled with insertion of an ion, typically a metal cation, in a vacant site of the solid. Nevertheless, different types of electrode materials are currently developed which include other $n$-type materials operating by insertion of e.g., protons or ammonium cations and p-type materials based on reversible anion intercalation. Several computational approaches to estimate the available potentials of organic insertion electrode materials have been used. At the single-molecule level, redox potentials can be calculated from the free energies of the oxidation/reduction as discussed in the beginning of this Section. Such calculated absolute potentials are then typically referenced against a metal electrode, e.g. $\mathrm{Li} / \mathrm{Li}^{+}, \mathrm{Na} / \mathrm{Na}^{+}$, or $\mathrm{Mg} / \mathrm{Mg}^{+}$, depending on which metal ion is being intercalated. However, molecular references like the ferrocene couple $\left(\mathrm{Fc}^{0} / \mathrm{Fc}^{+}\right)$are also used. The advantage of the latter is that their absolute redox potentials can be calculated with the same methodology, leading to the cancellation of systematic errors when comparing calculated voltages. The approach based on calculations of ionization potentials/electron affinities (sometimes also referred to as HOMO/LUMO energies) does not take into account the energetics of material-ion interactions. While staying at the molecular level of calculations, the potential with respect to the metal electrode can be calculated for metal-ion materials also from the molecular model 


$$
U=-\frac{E(O E M \cdot m M)-E(O E M)-m E(M)-m E_{c o h}(M)}{n m F}
$$

where $E(O E M \cdot m M)$ is the energy of the OEM's molecular model with $m$ coordinated metal atoms $M, E(O E M)$ the energy of the molecule only, $E(M)$ the energy of the free metal atom, $E_{c o h}(M)$ the cohesion energy of the metal electrode, $n$ is the charge of the cation, and $F$ is the Faraday constant. In addition to the maximum voltage, this method gives additional information about its state-ofcharge dependence and microscopic insights into electronic structure of the complex and the binding sites of the ions. Analogously, molecular cluster calculations can be used to calculate the absolute redox potentials of $p$-type materials based on anion insertion.

Beyond molecular calculations, the voltage of insertion electrode materials can be computed using periodic DFT calculations by calculating total energies at two different states of charge, corresponding to different concentrations of the intercalated ions. For a metal-ion OEM that during the charge or discharge cycles takes up ions $M^{+}$ions to reach their final concentration $x$, the corresponding voltage can be estimated as

$$
U=-\frac{E\left(M_{x} O E M\right)-E(O E M)-x E_{b u l k}(M)}{n x F}
$$

where $M_{x} O E M$ is now a solid-state material model with the concentration of cations $x$, and $E_{\text {bulk }}(M)$ is the energy of metal $M$ per single atom. Contrary to the molecular model, the solid-state approach takes into account the condensed-phase environment at the atomistic level and, in general, predicts higher voltages that are also closer to the experimental values. The approximations in Eqs. (5) and (6) neglect the zero-point vibrations and thermal contributions to the free energy of the reaction, which for solids are normally small compared to the electronic terms. Nevertheless, if there is a significant change in vibrational modes of molecular building blocks after the redox reaction, these contributions to the free energy may become important. In molecular calculations, they can be accounted for through harmonic vibrational analysis and model partition functions for translational, rotational, and vibrational degrees of freedom.

The stability of a redox-active compound depends on its ability to resist degradation reactions which can be due to many factors such as light, heat and unwanted (electro)chemical reactions with other components of the storage device. Various reactivity indices based on DFT can in principle be used to predict reactivity, (50) but often the most relevant degradation processes are known (51) and the thermodynamic stability can be estimated by computing the energies of all possible degradation products. $(52,53)$ When more detailed knowledge of the degradation mechanism is desired, the reaction barriers and consequently the kinetic rates can be estimated by computing the energies of the relevant transition states. $(54,55)$

\section{ORGANIC REDOX FLOW BATTERY MATERIALS}

Organic molecules are good candidates for RFB electrolytes thanks to the abundance and low cost of raw materials and the possibility of tailoring their properties through molecular engineering. Moreover, they tend to have faster electrochemical reaction kinetics compared to metal ions. $(56,57)$ The most important classes of redox-active organic molecules are the carbonyls (especially quinones), nitroxide radicals such as 2,2,6,6-tetramethylpiperidine-1-oxyl (TEMPO), and aromatic 
heterocycles such as viologens, pyrazines and pyrimidines. In the vast chemical space of organic molecules, it is challenging to find redox couples which satisfy all requirements for an RFB. Firstly, the molecules need to have reversible redox processes at suitable potentials giving the highest possible voltage within the electrochemical stability window of the solvent. Good solubility in all redox forms is equally important to achieve high energy density. Finally, the redox-active compounds should be stable, i.e. have chemical decomposition rates sufficiently low to keep capacity fade below $0.1 \%$ /day.(51) In this section, we will summarize how computational chemistry has supported and guided the search for better organic active materials for RFBs.

Although a fully organic non-aqueous RFB was first reported in 2011,(58) in recent years aqueous RFBs have received significantly more attention, probably due to their higher safety and lower cost. Already in the first report of a metal-free organic-inorganic aqueous RFB by Aziz and co-workers, DFT calculations were used to predict how different substitution patterns would affect the redox potentials and solvation free energies of a sulfonated anthraquinone.(59) The predicted change in the redox potential of one of the substituted compounds, which would increase the cell voltage, was confirmed experimentally. In the same year, the performance of an all-organic aqueous RFB was studied in detail by Yang et al. who found a good correlation between experimental and calculated redox potentials of sulfonated anthraquinones and benzoquinones.(57) The electrochemistry of quinones has been extensively studied from a computational perspective. $(35,37,60-64)$ In particular, Hammes-Schiffer and co-workers benchmarked calculations of the redox potentials and $\mathrm{pK}_{\mathrm{a}}$ values of a large number of quinones and found that hydrogen bonding, halogen substituents, charged substituents, and/or sterically bulky substituents can cause deviations from the expected linear relationship between the potentials of the $1 \mathrm{e}^{-}$(in acetonitrile) and $2 \mathrm{e}^{-} / 2 \mathrm{H}^{+}$(in acidic aqueous solution) redox processes.(36) TEMPO derivatives have also been found to be promising for RFBs, (65) often in combination with viologens, (66-69) but to our knowledge, only the electrochemical properties of some viologens have been studied computationally.(70-72) Ding et al. combined DFT calculations and experiments to understand the relationships between electronic structure and electrochemical properties of a series of quinones employed as the catholyte in a nonaqueous flow battery with metallic Li as the anode.(73) Aziz and co-workers, who in the meanwhile had developed alkaline aqueous RFBs based on anthraquinone derivatives and ferricyanide,(74) later proposed as candidates for negolytes the alloxazine family inspired by vitamin $B_{2}$, using DFT calculations to predict the properties of its hydroxyl-substituted derivatives.(75) A similar DFT-based prediction of the properties of substituted benzoquinones was included in a later study.(76) Kwon et al. used computed orbital energies to support their discussion of the electrochemical stability of non-aqueous RFB electrolytes based on a phenazine and a fluorenone.(77) Bachman et al.

performed a systematic computational study on anthraquinone derivatives for RFB applications.(78) They showed how the redox potentials are affected by coordination with components of Li salts and how they can be tuned by electron-withdrawing and -donating substituents as well as by changing the number of aromatic rings and keto groups. Moreover, they found that alkoxy substitution increases the solvation free energy in acetonitrile solvent, proposing it as a possible way to improve the solubility. Finally, they predicted that anthraquinone anions are relatively stable with regards to some bond-breaking reactions. Kim et al. compared experimental and computed redox potentials of a set of anthraquinone derivatives. They noted that DFT with implicit solvation has reasonable accuracy, except for some outliers where the interaction with water has to be modelled explicitly to correct the error.(41) 
In the last 6 years it became clear that since relatively inexpensive DFT calculations have acceptable predicting power, computational high-throughput screening of candidate molecules could speed up the development of new active materials for energy storage, including RFBs. $(70,79-81)$ This strategy consists in starting from a large pool of candidate structures and then down-selecting according to a "funnel" composed of successive tiers. At each tier, the candidates not satisfying constraints on a certain property are discarded, while the good ones make it to the next tier. For RFB electrolytes, it has been suggested to compute redox potential, solubility and stability in the first three tiers, $(70,79)$ but this choice of properties can be modified according to the specific goal of the study.

An accurate calculation of solubility requires knowledge of the sublimation energy and molar volume of the crystal and the solvation free energy. Since only the latter is easily computable while the first two are unknown for most compounds (especially if they are novel), the solvation free energy is often used as a qualitative metric of solubility. $(70,79,81)$ However, it would be desirable to achieve more reliable predictions of (especially) aqueous solubility. To this end, many predictive models based on experimental data sets or molecular descriptors have been developed $(82,83)$ and were employed in some RFB studies. $(80,84)$ A very promising method for predicting aqueous solubility of RFB candidates in high-throughput screening approaches was developed by Aspuru-Guzik and coworkers.(85) Tabor et al. addressed the problem of durability of quinones in water with a thorough investigation of the relationship between reduction potential and thermodynamic stability.(53) By performing a virtual screening of a library comprising more than $10^{5}$ quinone derivatives, they found that almost all quinones with reduction potential higher than $0.95 \mathrm{~V}$ vs. SHE are susceptible to Michael addition. This is one of the reasons why it is challenging to find quinones suitable as posolyte. Our group has recently performed a systematic computational study to understand how two redox-active units on the same molecule affect its properties.(84) Such a double redox molecule with sufficient separation $\Delta U$ between its two potentials would make it possible to build a symmetric RFB, i.e. with the same electrolyte in both tanks, a concept with multiple advantages (86) illustrated in Figure 2a. We found that the electronic interaction between redox units and intramolecular hydrogen bonding (Figure 2b) can significantly increase $\Delta U$ compared to molecules of the same size but with only one of the redox units (Figure 2c). The double redox design is also likely to increase solubility compared to the single redox reference. The properties can then be further tuned by adding substituents. These insights are valuable for guiding the design of organic electrolytes for symmetric RFBs. 
a)

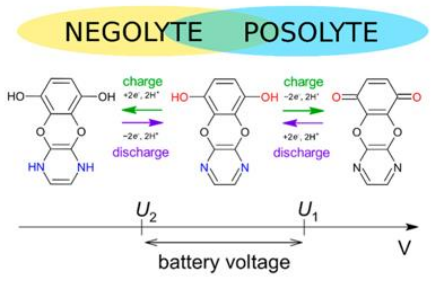

b)

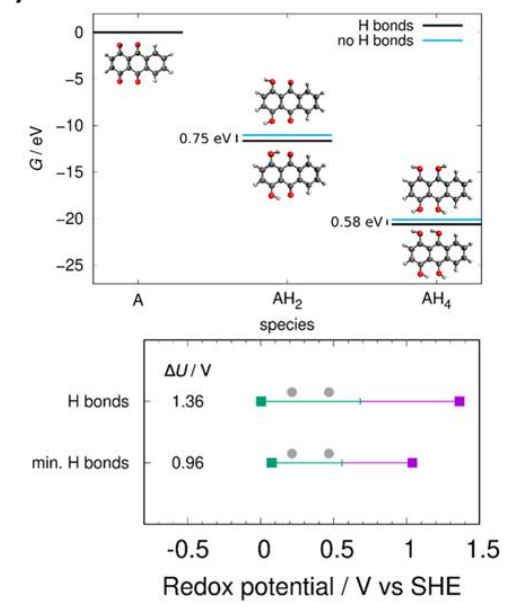

c)

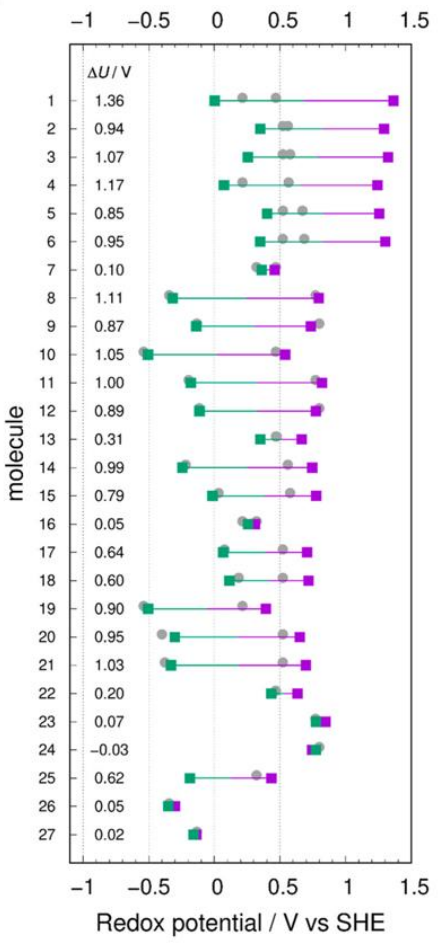

Figure 2. a) A molecule with two redox units, active at potentials $U_{1}$ and $U_{2}$, can act both as posolyte and negolyte in a symmetric RFB whose theoretical voltage is $\Delta U=U_{2}-U_{1}$. b) Intramolecular hydrogen bonds stabilise the reduced protonated form of double quinones and therefore increase its $\Delta U$ compared to the conformer without hydrogen bonds. c) The redox potentials of molecules with two redox units (coloured squares) are compared to the potentials of two separate molecules with only one of the redox units (grey dots). Adapted with permission from Fornari et al. ACS Materials Lett. 2020, 2, 3, 239-246. Copyright 2020 American Chemical Society.

\section{ORGANIC ELECTRODE MATERIALS}

Organic electrodes are a viable alternative to their inorganic counterparts for lithium-ion and postlithium battery technologies. An OEM is a multifunctional solid material that undergoes a reversible redox reaction but is also able to transport electrons and ions to the redox centres. Therefore, the list of requirements for an efficient OEM includes high specific energy, high electronic and ionic conductivity, low solubility, fast and reversible redox reaction, and high electrochemical stability. $(14,16)$ Several electrode design concepts have been developed, including small-molecule crystalline materials, $(87)$ organic frameworks, $(88,89)$ and disordered polymeric materials. $(11,12)$ Regardless of their morphology, OEMs are made from molecular building blocks that can be reversibly reduced or oxidized. Similar as for RFBs, several types of electroactive moieties have been proposed and tested for this purpose. $(12-14,16)$ The typical OEM materials include organic radicals, carbonyl, cyano, and azo compounds, phenazine derivatives, and molecules with multiple carbon bonds. For each of these classes of compounds, molecular engineering can be used to tune the electrochemical properties.(90) The viable strategies are e.g. functionalizing with electron-donating or electron-withdrawing groups to shift redox potentials, changing the $\pi$-electron conjugation pattern and the relative positions of electroactive groups, controlling dihedral angles between redox 
units, increasing the number of active sites in the material, introducing heteroatoms, and attaching highly polar groups to prevent dissolution in organic solvents.

Considering the vastness of the chemical space resulting from the possible molecular design strategies as well as the complexity of the physicochemical processes in OEMs, atomic-scale simulations have been widely used to gain detailed mechanistic insights and accelerate the design of novel materials.(91-93) As in most functional materials, the basic properties of OEMs result from an interplay between the microscopic morphology and the electronic structure. Therefore, any atomicscale simulation starts with choosing the atomistic model of the material and the electronic structure method. For the latter, the methods of choice are not surprisingly DFT or semiempirical methods as a compromise between accuracy and efficiency. The choice of the material model is far less trivial as the arrangement of molecular units and their mutual interactions depend on whether the OEM is crystalline, glassy, or polymeric. Therefore, the minimal reasonable model will depend on the specific properties targeted with computer simulations. Redox potentials are to a large extent determined by the electronic structure of the individual molecular units, so in many cases, DFT calculations on a single-molecule level can give valuable insights. This approach has been exploited in simulations supporting experimental work and aiming at providing additional mechanistic insights.(94-99) Single-molecule calculations have also proven helpful in formulating structureproperty relationships for OEMs (100-104) and direct in silico screening for new molecular precursors. $(105,106)$ Typically, such calculations are aiming foremost at the prediction of redox potentials using the computational electrochemistry methodology outlined in Section 2, but other thermodynamic properties like binding energies with ions or acidity constants can also be calculated. The modelling of such properties involves standard molecular DFT calculations, typically using Gaussian basis sets, hybrid exchange-correlation functionals, and implicit solvation models. However, single-molecule models have also been used to study the adsorption of organic redoxactive molecules on surfaces like pristine and doped graphene monolayers. $(107,108)$ The premise for such investigations in that stronger binding to the conducting substrate would result in lower solubility of an OEM and overall good electronic conductivity in the composite material. Such calculations of adsorbed molecules are typically done using DFT with periodic boundary conditions to account for the band structure of the substrate and avoid the finite-size effects. Because DFT calculations with hybrid functionals become very expensive in periodic electronic structure codes, GGA-level functionals are used. At the same time, a dispersion correction needs to be added to properly account for the van der Waals interactions between the surface and the adsorbate.

To go beyond the simple single-molecular-unit model one has to consider the effects of chemical bonding between the units as well as intermolecular interactions that are present in the solid state. This naturally makes the modelling more complicated but enables studying material properties that are manifested at slightly larger length and time scales, e.g. intermolecular interactions, charge transport properties, and storage of multiple charges. For example, a cluster model of crystalline OEMs allowed to gain some interesting mechanistic insights like the lack of metal atom ionization in sodium benzene tricarboxylate.(109) For polymeric OEMs, the natural step beyond monomer calculations is to consider oligomers. Such models are still easily tractable with DFT and allow to investigate some of the direct effects of interactions between covalently bonded monomers. Chen and Manzhos studied oligomer models of pristine and functionalized polyaniline which is a conducting polymer with potential applications as an organic cathode.(110) Going beyond the monomers enabled calculating voltages as a function of the degree of oxidation (state of charge), 
and a qualitative agreement with experiments was achieved. Araujo et al. calculated the electrochemical properties of polypyridine and polythiophene and the infinite chain limit by extrapolating the result of oligomers of varying length.(111) In our work, we studied dimers of directly linked 1,4-polyanthraquinone (14PAQ) which is an OEM with very good electrochemical properties.(112) Despite nearly orthogonal arrangement of neighbouring monomers, 14PAQ shows reasonably high conductivity, on par with organic semiconductors specifically designed for this purpose. By a combination of DFT-based calculations of charge transfer integrals and ab initio molecular dynamics, we have shown that the favourable transport properties are a consequence of the lone pair- $\pi$ interactions between neighbouring monomers (Figure 3a). This unexplored conjugation mechanism results in a remarkable resilience of electronic couplings to the dynamic disorder (Figure $3 \mathrm{~b}$ ) and opens new possibilities for the rational design of conducting OEMs.

a)

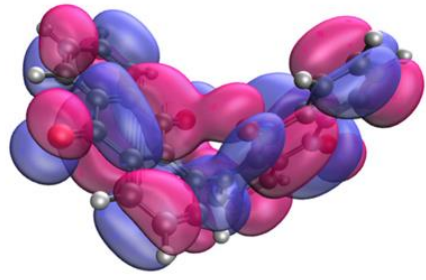

b)
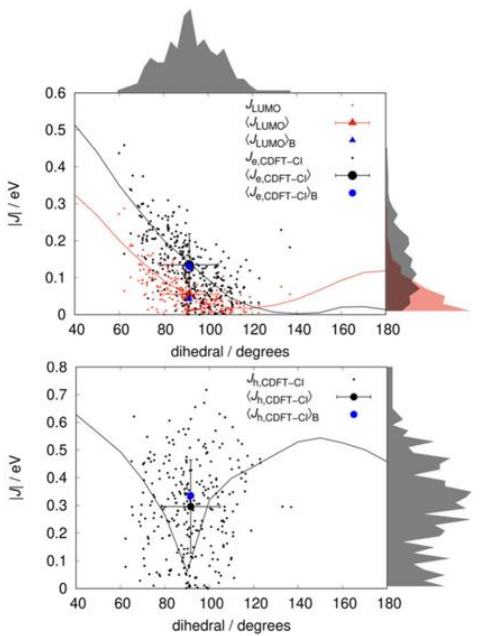

Figure 3. a) LUMO of a 1,4-linked anthraquinone dimer. A considerable overlap between the oxygen's lone pair and the $\pi$ system of the other monomer is visible. b) Electron (top) and hole (bottom) transfer integrals as a function of the dihedral angle between monomers, along the dihedral rotation coordinate (continuous lines) and at snapshots from an ab initio MD simulation (points). The distributions of the MD data are shown in the side panels. Charge transfer integrals were calculated as couplings between orbitals (Јноо, Lимо) and between charge-localized diabatic states (JCDF-CI). The latter method was found to be more reliable. Adapted from: Fornari, R. P. and de Silva, P. Chem. Eur. J. 2019, 25, 14651-14658. Reproduced with permission of John Wiley and Sons.

The biggest challenge in the modelling of polymer OEMs is accounting for the effects of long-range disorder and intermolecular interactions between molecular units in adjacent polymer strands. Reasonable models capturing these effects become too large to be treated solely at the ab initio level, which is particularly true when sampling of different conformations becomes necessary. To model the disordered morphology of polymer OEMs and its effect on their electrochemical properties, a combination of classical molecular dynamics (MD) and electronic structure calculations 
can be used. This multiscale approach was exploited by Kemper et al. to investigate the relation between the atomistic morphology of a radical-based polymer OEM and its charge transport properties. $(113,114)$ The computational workflow involved force-field parametrization, MD simulations of a system composed of almost 2500 monomer units, and quantum-mechanical calculations of electronic parameters present in the Marcus rate for the electron hopping between neighbouring monomers. The same group used a similar methodology to study the effects of OEM's swelling due to the solvent incorporation and binding of anions as a function of the state of charge of the battery.(115) Classical MD simulations have been also used by Chen et al. to simulate the morphology of polyaniline represented by a cell comprising 5 chains composed of 10 monomers each.(95) In the same work, the authors performed semiempirical DFTB electronic structure calculations to estimate the voltages as a function of the state of charge of the material. The model included explicit solvent molecules and salt ions.

While the disordered morphology affects the electrochemical properties of polymer OEMs, the molecular aggregation effects are also important in crystalline materials. However, thanks to the symmetry and relatively small unit cells, simulations of crystalline OEMs are somewhat easier. For such materials, periodic DFT can be used to model on an equal footing the morphology and the electronic properties.(116-125) To predict the crystal structure of OEMs, multi-level methods(126) and evolutionary algorithms $(120,121,124,125)$ have been employed. From the technical point of view, calculations of electrochemical properties of crystalline organic electrodes do not differ significantly from the modelling of inorganic electrode materials, and typically involve GGA-level calculations of the materials at different levels of ion intercalation (see eq. (6)). Because molecular crystals are held together by weak intermolecular forces, the use of dispersion corrections or van der Waals correlation functionals is indispensable. The solid-state modelling usually focusses on calculations of voltages which can differ from those based on molecular calculations even by $1 \mathrm{~V}$ as demonstrated for tetracyanides. $(119,127)$ Other relevant properties include band gaps and energy barriers for ion hopping. Small band gaps are favourable for higher electronic conductivities as they promote a higher concentration of charge carriers, typically polarons in OEMs. Similarly, small barriers for ion hopping make the diffusion of ions easier, thereby increasing the available power rating and decreasing the charging time of an OEM.

\section{CONCLUSION}

With the increasing focus on sustainable energy technologies computational studies of organic redox-active battery materials are becoming more and more common in the scientific literature. In this focus article, we reviewed the state of the art in modelling of organic redox flow battery and organic electrode materials. The picture emerging from this survey is that so far these modelling activities rely predominantly on well-established tools of computational electrochemistry, which we briefly discussed in Section 2. The most important figure of merit for redox-active materials is of course the reduction potential. The protocols based of DFT calculations, both molecular and periodic, offer a reasonably high accuracy at a modest computational cost. Nevertheless, the routine use of standard implicit solvation models appears as a weak spot in these workflows. The inaccurate description of solute-solvent hydrogen bonding, often present in aqueous RFBs, is one of the identified caveats.(32,41) The accuracy of these models also deteriorates with the increasing charge of the solute,(128) generating an imbalance in the description of molecules with different oxidation states. These issues become particularly grave for multiply charged anions, for which the electronic 
structure calculations often fail to converge as the additional electrons are not stabilized sufficiently. In these cases, cluster-continuum approaches may be the next best choice as they can offer a considerable improvement of accuracy, although they require more human work to determine the ideal number and placement of explicit solvent molecules. (45) That being said, the recent progress in the development of continuum and quantum embedding solvation models is likely to overcome some of these limitations.(129) Methods which improve the performance of implicit solvation models $(130,131)$ will allow the modelling of ever larger molecules and clusters; continuum embedding methods are rapidly evolving and make it possible to model electrochemical properties of electrode-electrolyte interfaces,(40) and now even charged species in periodic systems.(132) Therefore, we expect to see their more widespread applications to organic battery materials in the near future. While solvation free energies calculated with implicit solvents are often used as proxies for solubility, these are actually very poor predictors of the latter. Considering the importance of solubility for both RFB materials and OEMs, we anticipate that in the coming years more research will focus on its direct estimation. The strategies currently being explored are chemoinformatic models fitted to experimental data, $(82,83)$ statistical-mechanics-based methods like COSMORS,(133) and explicit calculations of crystal structures and sublimation free energies.(134) While organic materials have numerous advantages, perhaps the biggest disadvantage is their relatively low stability due to the undesired parasitic reactions. When the potential degradation reaction is known, standard computational chemistry tools can be used to assess its thermodynamic susceptibility and even calculate the reaction rate. $(54,55)$ However, in the case of multiple competing and a priori unknown reactions, computational modelling of a material's stability becomes a challenge. On this front, we expect that further development of algorithms for automated exploration of complex reaction networks (135-137) will bring a breakthrough in the near future.

While more or less automated calculations of redox potentials, solubilities, and stabilities will remain the main elements of computational discovery of new organic battery materials, focused studies of more complex processes are also becoming increasingly important. Such processes are often associated with phenomena occurring at a larger scale than single molecule, e.g. electronic and ionic transport in the bulk and across interfaces. The fully atomistic models that are able to represent them are either too large, especially for disordered materials like polymer OEMs, or statistical sampling of the configuration space is not practically feasible. Therefore, we anticipate further development of multiscale modelling techniques targeted specifically at electrochemical properties of battery materials.(138) This includes combining electronic structure and atomistic modelling methodology that has already been explored in the form of consecutive MD and DFT steps (113) or hybrid QM/MM simulations. $(46,47)$ Refinement and extensions of these approaches will enable more accurate calculations of electrochemical properties that depend on the structure and dynamics of the molecular environment of redox centres. Multiscale free energy calculations including explicit solvation should offer a much more robust approach to the modelling of electrochemically relevant reactions and physical processes. The atomistic simulations could be also used to parameterize mesoscopic models based on kinetic Monte Carlo simulations.(139-142) These in turn could be used to study the relation between OEMs' morphology and electronic/ionic conductivity, thereby giving direct insights into the available capacity and power density. At the same time, multiscale modelling techniques could enable studies of electrochemical processes at the interfaces, e.g. between the 
electrode and the dissolved organic RFB material, allowing for modelling of electrochemical and mass transport processes in the dielectric double layer.

\section{Funding Information}

This work was financially supported through an investment by Innovation Fund Denmark via the Grand Solutions project "ORBATS" file nr. 7046-00018B.

\section{References}

1. Whittingham MS. Electrical Energy Storage and Intercalation Chemistry. Science. 1976 Jun 11;192(4244):1126-7.

2. Mizushima K, Jones PC, Wiseman PJ, Goodenough JB. LixCoO2 $(0<x<-1)$ : A new cathode material for batteries of high energy density. Materials Research Bulletin. 1980 Jun;15(6):7839.

3. Moshtev R, Johnson B. State of the art of commercial Li ion batteries. Journal of Power Sources. 2000 Dec;91(2):86-91.

4. Goodenough JB, Kim Y. Challenges for rechargeable batteries. Journal of Power Sources. 2011 Aug;196(16):6688-94.

5. Cho J, Jeong S, Kim Y. Commercial and research battery technologies for electrical energy storage applications. Progress in Energy and Combustion Science. 2015 Jun;48:84-101.

6. Weber AZ, Mench MM, Meyers JP, Ross PN, Gostick JT, Liu Q. Redox flow batteries: a review. J Appl Electrochem. 2011 Sep 2;41(10):1137.

7. Noack J, Roznyatovskaya N, Herr T, Fischer P. The Chemistry of Redox-Flow Batteries. Angewandte Chemie International Edition. 2015;54(34):9776-809.

8. Skyllas-Kazacos M, Rychcik M, Robins RG, Fane AG, Green MA. New All-Vanadium Redox Flow Cell. J Electrochem Soc. 1986 May 1;133(5):1057.

9. Poizot P, Dolhem F, Gaubicher J. Progress in all-organic rechargeable batteries using cationic and anionic configurations: Toward low-cost and greener storage solutions? Current Opinion in Electrochemistry. 2018 Jun 1;9:70-80.

10. Gracia R, Mecerreyes D. Polymers with redox properties: materials for batteries, biosensors and more. Polymer Chemistry. 2013;4(7):2206-14.

11. Novák P, Müller K, Santhanam KSV, Haas O. Electrochemically Active Polymers for Rechargeable Batteries. Chemical Reviews. 1997;97(1):207-82.

12. Muench S, Wild A, Friebe C, Häupler B, Janoschka T, Schubert US. Polymer-Based Organic Batteries. Chemical Reviews. 2016 Aug 24;116(16):9438-84.

13. Nyholm L, Nyström G, Mihranyan A, Strømme M. Toward Flexible Polymer and Paper-Based Energy Storage Devices. Advanced Materials. 2011;23(33):3751-69.

14. Schon TB, McAllister BT, Li P-F, Seferos DS. The rise of organic electrode materials for energy storage. Chemical Society Reviews. 2016;45(22):6345-404. 
15. Lu Y, Zhang Q, Li L, Niu Z, Chen J. Design Strategies toward Enhancing the Performance of Organic Electrode Materials in Metal-Ion Batteries. Chem. 2018 Dec 13;4(12):2786-813.

16. Liang Y, Tao Z, Chen J. Organic Electrode Materials for Rechargeable Lithium Batteries. Advanced Energy Materials. 2012 Jul;2(7):742-69.

17. Soloveichik GL. Flow Batteries: Current Status and Trends. Chem Rev. 2015 Oct 28;115(20):11533-58.

18. Leung P, Shah AA, Sanz L, Flox C, Morante JR, Xu Q, et al. Recent developments in organic redox flow batteries: A critical review. Journal of Power Sources. 2017 Aug 31;360:243-83.

19. Wei X, Pan W, Duan W, Hollas A, Yang Z, Li B, et al. Materials and Systems for Organic Redox Flow Batteries: Status and Challenges. ACS Energy Lett. 2017 Sep 8;2(9):2187-204.

20. Ding Y, Zhang C, Zhang L, Zhou Y, Yu G. Molecular engineering of organic electroactive materials for redox flow batteries. Chem Soc Rev. 2018 Jan 2;47(1):69-103.

21. Wedege K, Dražević E, Konya D, Bentien A. Organic Redox Species in Aqueous Flow Batteries: Redox Potentials, Chemical Stability and Solubility. Scientific Reports. 2016 Dec 14;6(1):1-13.

22. Marenich AV, Ho J, L. Coote M, J. Cramer C, G. Truhlar D. Computational electrochemistry: prediction of liquid-phase reduction potentials. Physical Chemistry Chemical Physics. 2014;16(29):15068-106.

23. Konezny SJ, Doherty MD, Luca OR, Crabtree RH, Soloveichik GL, Batista VS. Reduction of Systematic Uncertainty in DFT Redox Potentials of Transition-Metal Complexes. J Phys Chem C. 2012 Mar 15;116(10):6349-56.

24. Ho J. Are thermodynamic cycles necessary for continuum solvent calculation of pKas and reduction potentials? Phys Chem Chem Phys. 2014 Dec 23;17(4):2859-68.

25. Tomasi J, Persico M. Molecular Interactions in Solution: An Overview of Methods Based on Continuous Distributions of the Solvent. Chem Rev. 1994 Nov 1;94(7):2027-94.

26. Cramer CJ, Truhlar DG. Implicit Solvation Models: Equilibria, Structure, Spectra, and Dynamics. Chem Rev. 1999 Aug 11;99(8):2161-200.

27. Miertuš S, Scrocco E, Tomasi J. Electrostatic interaction of a solute with a continuum. A direct utilizaion of $\mathrm{AB}$ initio molecular potentials for the prevision of solvent effects. Chemical Physics. 1981 Feb 1;55(1):117-29.

28. Barone V, Cossi M. Quantum Calculation of Molecular Energies and Energy Gradients in Solution by a Conductor Solvent Model. J Phys Chem A. 1998 Mar 1;102(11):1995-2001.

29. Cossi M, Rega N, Scalmani G, Barone V. Energies, structures, and electronic properties of molecules in solution with the C-PCM solvation model. Journal of Computational Chemistry. 2003 Apr 30;24(6):669-81.

30. Klamt A, Schüürmann G. COSMO: a new approach to dielectric screening in solvents with explicit expressions for the screening energy and its gradient. Journal of the Chemical Society, Perkin Transactions 2. 1993;0(5):799-805. 
31. Marenich AV, Cramer CJ, Truhlar DG. Universal Solvation Model Based on Solute Electron Density and on a Continuum Model of the Solvent Defined by the Bulk Dielectric Constant and Atomic Surface Tensions. J Phys Chem B. 2009 May 7;113(18):6378-96.

32. Ho J, Klamt A, Coote ML. Comment on the Correct Use of Continuum Solvent Models. J Phys Chem A. 2010 Dec 30;114(51):13442-4.

33. Hammerich O, Speiser B, editors. Organic electrochemistry. Fifth edition revised and expanded. Boca Raton: CRC Press, Taylor \& Francis Group; 2016. 1712 p.

34. Quan M, Sanchez D, Wasylkiw MF, Smith DK. Voltammetry of Quinones in Unbuffered Aqueous Solution: Reassessing the Roles of Proton Transfer and Hydrogen Bonding in the Aqueous Electrochemistry of Quinones. J Am Chem Soc. 2007 Oct 1;129(42):12847-56.

35. Johnsson Wass JRT, Ahlberg E, Panas I, Schiffrin DJ. Quantum Chemical Modeling of the Reduction of Quinones. The Journal of Physical Chemistry A. 2006 Feb;110(5):2005-20.

36. Huynh MT, Anson CW, Cavell AC, Stahl SS, Hammes-Schiffer S. Quinone 1 e- and 2 e- $/ 2$ $\mathrm{H}+$ Reduction Potentials: Identification and Analysis of Deviations from Systematic Scaling Relationships. J Am Chem Soc. 2016 Dec 14;138(49):15903-10.

37. Namazian M, Coote ML. Accurate Calculation of Absolute One-Electron Redox Potentials of Some para-Quinone Derivatives in Acetonitrile. J Phys Chem A. 2007 Aug 1;111(30):722732.

38. Calbo J, Viruela R, Ortí E, Aragó J. Relationship between Electron Affinity and Half-Wave Reduction Potential: A Theoretical Study on Cyclic Electron-Acceptor Compounds. ChemPhysChem. 2016 Dec 5;17(23):3881-90.

39. Isegawa M, Neese F, Pantazis DA. Ionization Energies and Aqueous Redox Potentials of Organic Molecules: Comparison of DFT, Correlated ab Initio Theory and Pair Natural Orbital Approaches. J Chem Theory Comput. 2016 May 10;12(5):2272-84.

40. Andreussi O, Fisicaro G. Continuum embeddings in condensed-matter simulations. International Journal of Quantum Chemistry. 2019;119(1):e25725.

41. Kim H, Goodson T, Zimmerman PM. Achieving Accurate Reduction Potential Predictions for Anthraquinones in Water and Aprotic Solvents: Effects of Inter- and Intramolecular HBonding and Ion Pairing. The Journal of Physical Chemistry C. 2016 Oct 6;120(39):22235-47.

42. Pliego JR, Riveros JM. The Cluster-Continuum Model for the Calculation of the Solvation Free Energy of Ionic Species. J Phys Chem A. 2001 Aug 1;105(30):7241-7.

43. Thapa B, Schlegel HB. Density Functional Theory Calculation of $\mathrm{p}$ Ka's of Thiols in Aqueous Solution Using Explicit Water Molecules and the Polarizable Continuum Model. The Journal of Physical Chemistry A. 2016 Jul 21;120(28):5726-35.

44. Guo C, Wang W, Feng W, Li P. Insights into the one-electron reduction behavior of tetrachloro-o-benzoquinone: a DFT and molecular dynamics study. RSC Adv. 2017 Feb $21 ; 7(21): 12775-82$.

45. Pliego JR, Riveros JM. Hybrid discrete-continuum solvation methods. WIREs Computational Molecular Science. 2020;10(2):e1440. 
46. Wang L-P, Van Voorhis T. A Polarizable QM/MM Explicit Solvent Model for Computational Electrochemistry in Water. J Chem Theory Comput. 2012 Feb 14;8(2):610-7.

47. Vaissier V, Van Voorhis T. Adiabatic Approximation in Explicit Solvent Models of RedOx Chemistry. J Chem Theory Comput. 2016 Oct 11;12(10):5111-6.

48. Sterling CM, Bjornsson R. Multistep Explicit Solvation Protocol for Calculation of Redox Potentials. J Chem Theory Comput. 2019 Jan 8;15(1):52-67.

49. Basdogan Y, Groenenboom MC, Henderson E, De S, Rempe SB, Keith JA. Machine LearningGuided Approach for Studying Solvation Environments. J Chem Theory Comput. 2020 Jan 14;16(1):633-42.

50. Domingo LR, Ríos-Gutiérrez M, Pérez P. Applications of the Conceptual Density Functional Theory Indices to Organic Chemistry Reactivity. Molecules. 2016 Jun;21(6):748.

51. Kwabi DG, Ji Y, Aziz MJ. Electrolyte Lifetime in Aqueous Organic Redox Flow Batteries: A Critical Review. Chem Rev [Internet]. 2020 Feb 13 [cited 2020 Feb 26]; Available from: https://doi.org/10.1021/acs.chemrev.9b00599

52. Gerhardt MR, Tong L, Gómez-Bombarelli R, Chen Q, Marshak MP, Galvin CJ, et al. Anthraquinone Derivatives in Aqueous Flow Batteries. Advanced Energy Materials. 2017 Apr;7(8):1601488.

53. Tabor DP, Gómez-Bombarelli R, Tong L, Gordon RG, Aziz MJ, Aspuru-Guzik A. Mapping the frontiers of quinone stability in aqueous media: implications for organic aqueous redox flow batteries. J Mater Chem A. 2019 May 21;7(20):12833-41.

54. Truhlar DG, Pliego JR. Transition State Theory and Chemical Reaction Dynamics in Solution. In: Continuum Solvation Models in Chemical Physics: Theory and Application. John Wiley \& Sons; 2008.

55. Fernández-Ramos A, Miller JA, Klippenstein SJ, Truhlar DG. Modeling the Kinetics of Bimolecular Reactions. Chem Rev. 2006 Nov 1;106(11):4518-84.

56. Song Z, Zhou H. Towards sustainable and versatile energy storage devices: an overview of organic electrode materials. Energy \& Environmental Science. 2013;6(8):2280.

57. Yang B, Hoober-Burkhardt L, Wang F, Prakash GKS, Narayanan SR. An Inexpensive Aqueous Flow Battery for Large-Scale Electrical Energy Storage Based on Water-Soluble Organic Redox Couples. J Electrochem Soc. 2014 Jun 19;161(9):A1371.

58. Li Z, Li S, Liu S, Huang K, Fang D, Wang F, et al. Electrochemical Properties of an AllOrganic Redox Flow Battery Using 2,2,6,6-Tetramethyl-1-Piperidinyloxy and NMethylphthalimide. Electrochem Solid-State Lett. 2011 Oct 26;14(12):A171.

59. Huskinson B, Marshak MP, Suh C, Er S, Gerhardt MR, Galvin CJ, et al. A metal-free organicinorganic aqueous flow battery. Nature. 2014 Jan;505(7482):195-8.

60. Namazian M, Almodarresieh HA, Noorbala MR, Zare HR. DFT calculation of electrode potentials for substituted quinones in aqueous solution. Chemical Physics Letters. 2004 Oct 1;396(4):424-8. 
61. Frontana C, Vázquez-Mayagoitia Á, Garza J, Vargas R, González I. Substituent Effect on a Family of Quinones in Aprotic Solvents: An Experimental and Theoretical Approach. J Phys Chem A. 2006 Aug 1;110(30):9411-9.

62. Zare HR, Eslami M, Namazian M, Coote ML. Experimental and Theoretical Studies of Redox Reactions of o-Chloranil in Aqueous Solution. J Phys Chem B. 2009 Jun 11;113(23):8080-5.

63. Zhu X-Q, Wang C-H. Accurate Estimation of the One-Electron Reduction Potentials of Various Substituted Quinones in DMSO and CH3CN. J Org Chem. 2010 Aug 6;75(15):503747.

64. Wang Z, Li A, Gou L, Ren J, Zhai G. Computational electrochemistry study of derivatives of anthraquinone and phenanthraquinone analogues: the substitution effect. RSC Adv. 2016 Sep 16;6(92):89827-35.

65. Wei X, Xu W, Vijayakumar M, Cosimbescu L, Liu T, Sprenkle V, et al. TEMPO-Based Catholyte for High-Energy Density Nonaqueous Redox Flow Batteries. Advanced Materials. 2014;26(45):7649-53.

66. Janoschka T, Martin N, Martin U, Friebe C, Morgenstern S, Hiller H, et al. An aqueous, polymer-based redox-flow battery using non-corrosive, safe, and low-cost materials. Nature. 2015 Nov;527(7576):78-81.

67. Janoschka T, Martin N, Hager MD, Schubert US. An Aqueous Redox-Flow Battery with High Capacity and Power: The TEMPTMA/MV System. Angewandte Chemie International Edition. 2016;55(46):14427-30.

68. Liu T, Wei X, Nie Z, Sprenkle V, Wang W. A Total Organic Aqueous Redox Flow Battery Employing a Low Cost and Sustainable Methyl Viologen Anolyte and 4-HO-TEMPO Catholyte. Advanced Energy Materials. 2016;6(3):1501449.

69. Janoschka T, Friebe C, Hager MD, Martin N, Schubert US. An Approach Toward Replacing Vanadium: A Single Organic Molecule for the Anode and Cathode of an Aqueous Redox-Flow Battery. ChemistryOpen. 2017;6(2):216-20.

70. Cheng L, Assary RS, Qu X, Jain A, Ong SP, Rajput NN, et al. Accelerating Electrolyte Discovery for Energy Storage with High-Throughput Screening. J Phys Chem Lett. 2015 Jan 15;6(2):283-91.

71. DeBruler C, Hu B, Moss J, Liu X, Luo J, Sun Y, et al. Designer Two-Electron Storage Viologen Anolyte Materials for Neutral Aqueous Organic Redox Flow Batteries. Chem. 2017 Dec 14;3(6):961-78.

72. DeBruler C, Hu B, Moss J, Luo J, Liu TL. A Sulfonate-Functionalized Viologen Enabling Neutral Cation Exchange, Aqueous Organic Redox Flow Batteries toward Renewable Energy Storage. ACS Energy Lett. 2018 Mar 9;3(3):663-8.

73. Ding Y, Li Y, Yu G. Exploring Bio-inspired Quinone-Based Organic Redox Flow Batteries: A Combined Experimental and Computational Study. Chem. 2016 Nov;1(5):790-801.

74. Lin K, Chen Q, Gerhardt MR, Tong L, Kim SB, Eisenach L, et al. Alkaline quinone flow battery. Science. 2015 Sep 25;349(6255):1529-32.

75. Lin K, Gómez-Bombarelli R, Beh ES, Tong L, Chen Q, Valle A, et al. A redox-flow battery with an alloxazine-based organic electrolyte. Nat Energy. 2016 Jul 18;1(9):1-8. 
76. Yang Z, Tong L, Tabor DP, Beh ES, Goulet M-A, De Porcellinis D, et al. Alkaline Benzoquinone Aqueous Flow Battery for Large-Scale Storage of Electrical Energy. Advanced Energy Materials. 2018 Mar;8(8):1702056.

77. Kwon G, Lee S, Hwang J, Shim H-S, Lee B, Lee MH, et al. Multi-redox Molecule for HighEnergy Redox Flow Batteries. Joule. 2018 Sep 19;2(9):1771-82.

78. Bachman JE, Curtiss LA, Assary RS. Investigation of the Redox Chemistry of Anthraquinone Derivatives Using Density Functional Theory. The Journal of Physical Chemistry A. 2014 Sep 25;118(38):8852-60.

79. Er S, Suh C, Marshak MP, Aspuru-Guzik A. Computational design of molecules for an allquinone redox flow battery. Chemical Science. 2015;6(2):885-93.

80. Pineda Flores SD, Martin-Noble GC, Phillips RL, Schrier J. Bio-Inspired Electroactive Organic Molecules for Aqueous Redox Flow Batteries. 1. Thiophenoquinones. J Phys Chem C. 2015 Sep 24;119(38):21800-9.

81. Moon Y, Han Y-K. Computational screening of organic molecules as redox active species in redox flow batteries. Current Applied Physics. 2016 Sep 1;16(9):939-43.

82. Hou TJ, Xia K, Zhang W, Xu XJ. ADME Evaluation in Drug Discovery. 4. Prediction of Aqueous Solubility Based on Atom Contribution Approach. J Chem Inf Comput Sci. 2004 Jan 1;44(1):266-75.

83. Wang J, Hou T. Recent Advances on Aqueous Solubility Prediction. Combinatorial Chemistry \& High Throughput Screening. 2011 Jun 1;14(5):328-38.

84. Fornari RP, Mesta M, Hjelm J, Vegge T, de Silva P. Molecular Engineering Strategies for Symmetric Aqueous Organic Redox Flow Batteries. ACS Materials Lett. 2020 Feb 7;239-46.

85. Kim S, Jinich A, Aspuru-Guzik A. MultiDK: A Multiple Descriptor Multiple Kernel Approach for Molecular Discovery and Its Application to Organic Flow Battery Electrolytes. J Chem Inf Model. 2017 Apr 24;57(4):657-68.

86. Potash RA, McKone JR, Conte S, Abruña HD. On the Benefits of a Symmetric Redox Flow Battery. J Electrochem Soc. 2016 Jan 1;163(3):A338-44.

87. Heiska J, Nisula M, Karppinen M. Organic electrode materials with solid-state battery technology. J Mater Chem A. 2019 Aug 13;7(32):18735-58.

88. DeBlase CR, Hernández-Burgos K, Silberstein KE, Rodríguez-Calero GG, Bisbey RP, Abruña HD, et al. Rapid and Efficient Redox Processes within 2D Covalent Organic Framework Thin Films. ACS Nano. 2015 Mar 24;9(3):3178-83.

89. Sun T, Xie J, Guo W, Li D-S, Zhang Q. Covalent-Organic Frameworks: Advanced Organic Electrode Materials for Rechargeable Batteries. Advanced Energy Materials. 2020;1904199.

90. Lu Y, Zhang Q, Li L, Niu Z, Chen J. Design Strategies toward Enhancing the Performance of Organic Electrode Materials in Metal-Ion Batteries. Chem. 2018 Dec;4(12):2786-813.

91. Manzhos S. Organic electrode materials for lithium and post-lithium batteries: an ab initio perspective on design. Current Opinion in Green and Sustainable Chemistry. 2019 Jun 1;17:814. 
92. Manzhos S. Aggregate-State Effects in the Atomistic Modeling of Organic Materials for Electrochemical Energy Conversion and Storage Devices: A Perspective. Molecules. 2020 May 9;25(9):2233.

93. Lüder J, Manzhos S. First-Principle Insights Into Molecular Design for High-Voltage Organic Electrode Materials for Mg Based Batteries. Front Chem. 2020 Feb 18;8:83.

94. Karlsson C, Jämstorp E, Strømme M, Sjödin M. Computational Electrochemistry Study of 16 Isoindole-4,7-diones as Candidates for Organic Cathode Materials. The Journal of Physical Chemistry C. 2012 Feb 9;116(5):3793-801.

95. Chen Y, Lüder J, Ng M-F, Sullivan M, Manzhos S. Polyaniline and CN-functionalized polyaniline as organic cathodes for lithium and sodium ion batteries: a combined molecular dynamics and density functional tight binding study in solid state. Phys Chem Chem Phys. 2017 Dec 20;20(1):232-7.

96. Renault S, Oltean VA, Araujo CM, Grigoriev A, Edström K, Brandell D. Superlithiation of Organic Electrode Materials: The Case of Dilithium Benzenedipropiolate. Chem Mater. 2016 Mar 22;28(6):1920-6.

97. Miao L, Liu L, Zhang K, Chen J. Molecular Design Strategy for High-Redox-Potential and Poorly Soluble n-Type Phenazine Derivatives as Cathode Materials for Lithium Batteries. ChemSusChem [Internet]. 2020 Jan 22 [cited 2020 Apr 8];n/a(n/a). Available from: https://chemistry-europe.onlinelibrary.wiley.com/doi/full/10.1002/cssc.202000004

98. Dardenne N, Blase X, Hautier G, Charlier J-C, Rignanese G-M. Ab Initio Calculations of Open-Cell Voltage in Li-Ion Organic Radical Batteries. J Phys Chem C. 2015 Oct 15;119(41):23373-8.

99. Chen Y, Cho C-R, Manzhos S. Lithium Attachment to C60 and Nitrogen- and Boron-Doped C60: A Mechanistic Study. Materials. 2019 Jul 3;12(13):2136.

100. Burkhardt SE, Bois J, Tarascon J-M, Hennig RG, Abruña HD. Li-Carboxylate Anode Structure-Property Relationships from Molecular Modeling. Chem Mater. 2013 Jan 22;25(2):132-41.

101. Hernández-Burgos K, Burkhardt SE, Rodríguez-Calero GG, Hennig RG, Abruña HD. Theoretical Studies of Carbonyl-Based Organic Molecules for Energy Storage Applications: The Heteroatom and Substituent Effect. The Journal of Physical Chemistry C. 2014 Mar 27;118(12):6046-51.

102. Tomerini D, Gatti C, Frayret C. Engineering of unsubstituted quinoid-like frameworks enabling $2 \mathrm{~V}$ vs. $\mathrm{Li} / \mathrm{Li}$ redox voltage tunability and related derivatives. Phys Chem Chem Phys. 2015 Mar 27;17(14):8604-8.

103. Tomerini D, Gatti C, Frayret C. Playing with isomerism and N substitution in pentalenedione derivatives for organic electrode batteries: how high are the stakes? Phys Chem Chem Phys. 2016 Jan 20;18(4):2442-8.

104. Lüder J, Cheow MH, Manzhos S. Understanding doping strategies in the design of organic electrode materials for $\mathrm{Li}$ and $\mathrm{Na}$ ion batteries: an electronic structure perspective. Phys Chem Chem Phys. 2017 May 24;19(20):13195-209. 
105. Araujo RB, Banerjee A, Panigrahi P, Yang L, Strømme M, Sjödin M, et al. Designing strategies to tune reduction potential of organic molecules for sustainable high capacity battery application. Journal of Materials Chemistry A. 2017;5(9):4430-54.

106. Allam O, Woo Cho B, Chul Kim K, Soon Jang S. Application of DFT-based machine learning for developing molecular electrode materials in Li-ion batteries. RSC Advances.

2018;8(69):39414-20.

107. Yu Y-X. A dispersion-corrected DFT study on adsorption of battery active materials anthraquinone and its derivatives on monolayer graphene and h-BN. J Mater Chem A. 2014 May 21;2(23):8910-7.

108. Chen Y, Manzhos S. Lithium and sodium storage on tetracyanoethylene (TCNE) and TCNE(doped)-graphene complexes: A computational study. Materials Chemistry and Physics. 2015 Apr 15;156:180-7.

109. Tripathi A, Chen Y, Padhy H, Manzhos S, Balaya P. Experimental and Theoretical Studies of Trisodium-1,3,5-Benzene Tricarboxylate as a Low-Voltage Anode Material for Sodium-Ion Batteries. Energy Technol. 2019 May;7(5):1801030.

110. Chen Y, Manzhos S. Voltage and capacity control of polyaniline based organic cathodes: An ab initio study. Journal of Power Sources. 2016 Dec 30;336:126-31.

111. Araujo RB, Banerjee A, Panigrahi P, Yang L, Sjödin M, Strømme M, et al. Assessing the electrochemical properties of polypyridine and polythiophene for prospective applications in sustainable organic batteries. Phys Chem Chem Phys. 2017 Jan 25;19(4):3307-14.

112. Fornari RP, de Silva P. Unexpectedly Large Couplings Between Orthogonal Units in Anthraquinone Polymers. Chemistry - A European Journal. 2019;25(64):14651-8.

113. Kemper TW, Larsen RE, Gennett T. Relationship between Molecular Structure and Electron Transfer in a Polymeric Nitroxyl-Radical Energy Storage Material. J Phys Chem C. 2014 Aug 7;118(31):17213-20.

114. Kemper TW, Larsen RE, Gennett T. Density of States and the Role of Energetic Disorder in Charge Transport in an Organic Radical Polymer in the Solid State. J Phys Chem C. 2015 Sep 17;119(37):21369-75.

115. Kemper TW, Gennett T, Larsen RE. Molecular Dynamics Simulation Study of Solvent and State of Charge Effects on Solid-Phase Structure and Counterion Binding in a Nitroxide Radical Containing Polymer Energy Storage Material. J Phys Chem C. 2016 Nov $17 ; 120(45): 25639-46$.

116. Chen Y, Wu Z, Sun S. First-Principles Study of an Ethoxycarbonyl-Based Organic Electrode Material of Lithium Battery. J Phys Chem C. 2014 Sep 25;118(38):21813-8.

117. Sun S, Chen Y, Yu J. High Throughput Screening of Organic Electrode Materials for Lithium Battery by Theoretical Method. J Phys Chem C. 2015 Nov 19;119(46):25770-7.

118. Chen Y, Sun S, Wang X, Shi Q. Study of Lithium Migration Pathways in the Organic Electrode Materials of Li-Battery by Dispersion-Corrected Density Functional Theory. J Phys Chem C. 2015 Nov 19;119(46):25719-25.

119. Chen Y, Manzhos S. A comparative computational study of lithium and sodium insertion into van der Waals and covalent tetracyanoethylene (TCNE)-based crystals as promising materials 
for organic lithium and sodium ion batteries. Phys Chem Chem Phys. 2016 Mar 23;18(13):8874-80.

120. Yamashita T, Momida H, Oguchi T. Crystal structure predictions of NaxC6O6 for sodium-ion batteries: First-principles calculations with an evolutionary algorithm. Electrochimica Acta. 2016 Mar 20;195:1-8.

121. Araujo RB, Banerjee A, Ahuja R. Divulging the Hidden Capacity and Sodiation Kinetics of NaxC6C14O2: A High Voltage Organic Cathode for Sodium Rechargeable Batteries. J Phys Chem C. 2017 Jul 6;121(26):14027-36.

122. Banerjee A, Araujo RB, Sjödin M, Ahuja R. Identifying the tuning key of disproportionation redox reaction in terephthalate: A Li-based anode for sustainable organic batteries. Nano Energy. 2018 May 1;47:301-8.

123. Padhy H, Chen Y, Lüder J, Gajella SR, Manzhos S, Balaya P. Charge and Discharge Processes and Sodium Storage in Disodium Pyridine-2,5-Dicarboxylate Anode-Insights from Experiments and Theory. Advanced Energy Materials. 2018;8(7):1701572.

124. Marchiori CFN, Brandell D, Araujo CM. Predicting Structure and Electrochemistry of Dilithium Thiophene-2,5-Dicarboxylate Electrodes by Density Functional Theory and Evolutionary Algorithms. J Phys Chem C. 2019 Feb 28;123(8):4691-700.

125. Carvalho RP, Marchiori CFN, Brandell D, Araujo CM. Tuning the Electrochemical Properties of Organic Battery Cathode Materials: Insights from Evolutionary Algorithm DFT Calculations. ChemSusChem [Internet]. 2020 Feb 14 [cited 2020 Apr 8];n/a(n/a). Available from: https://chemistry-europe.onlinelibrary.wiley.com/doi/full/10.1002/cssc.201903450

126. Seo D-H, Kim H, Kim H, Goddard WA, Kang K. The predicted crystal structure of Li4C6O6, an organic cathode material for Li-ion batteries, from first-principles multi-level computational methods. Energy Environ Sci. 2011;4(12):4938.

127. Chen Y, Manzhos S. A computational study of lithium interaction with tetracyanoethylene (TCNE) and tetracyaniquinodimethane (TCNQ) molecules. Phys Chem Chem Phys. 2016;18(3):1470-7.

128. Thompson JD, Cramer CJ, Truhlar DG. New Universal Solvation Model and Comparison of the Accuracy of the SM5.42R, SM5.43R, C-PCM, D-PCM, and IEF-PCM Continuum Solvation Models for Aqueous and Organic Solvation Free Energies and for Vapor Pressures. J Phys Chem A. 2004 Aug 1;108(31):6532-42.

129. Frediani L, Andreussi O, Kulik HJ. Coding solvation: challenges and opportunities. International Journal of Quantum Chemistry. 2019;119(1):e25839.

130. Stamm B, Lagardère L, Scalmani G, Gatto P, Cancès E, Piquemal J-P, et al. How to make continuum solvation incredibly fast in a few simple steps: A practical guide to the domain decomposition paradigm for the conductor-like screening model. International Journal of Quantum Chemistry. 2019;119(1):e25669.

131. Liu F, Sanchez DM, Kulik HJ, Martínez TJ. Exploiting graphical processing units to enable quantum chemistry calculation of large solvated molecules with conductor-like polarizable continuum models. International Journal of Quantum Chemistry. 2019;119(1):e25760. 
132. Tölle J, Gomes ASP, Ramos P, Pavanello M. Charged-cell periodic DFT simulations via an impurity model based on density embedding: Application to the ionization potential of liquid water. International Journal of Quantum Chemistry. 2019;119(1):e25801.

133. Klamt A. Conductor-like Screening Model for Real Solvents: A New Approach to the Quantitative Calculation of Solvation Phenomena. J Phys Chem. 1995 Feb 1;99(7):2224-35.

134. Palmer DS, Llinàs A, Morao I, Day GM, Goodman JM, Glen RC, et al. Predicting Intrinsic Aqueous Solubility by a Thermodynamic Cycle. Mol Pharmaceutics. 2008 Apr 1;5(2):266-79.

135. Zimmerman PM. Automated discovery of chemically reasonable elementary reaction steps. Journal of Computational Chemistry. 2013;34(16):1385-92.

136. Simm GN, Vaucher AC, Reiher M. Exploration of Reaction Pathways and Chemical Transformation Networks. J Phys Chem A. 2019 Jan 17;123(2):385-99.

137. Gao CW, Allen JW, Green WH, West RH. Reaction Mechanism Generator: Automatic construction of chemical kinetic mechanisms. Computer Physics Communications. 2016 Jun 1;203:212-25.

138. Franco AA, Rucci A, Brandell D, Frayret C, Gaberscek M, Jankowski P, et al. Boosting Rechargeable Batteries R\&D by Multiscale Modeling: Myth or Reality? Chem Rev. 2019 Apr 10;119(7):4569-627.

139. Shukla G, del Olmo Diaz D, Thangavel V, Franco AA. Self-Organization of Electroactive Suspensions in Discharging Slurry Batteries: A Mesoscale Modeling Investigation. ACS Appl Mater Interfaces. 2017 May 31;9(21):17882-9.

140. Shukla G, Franco AA. Handling Complexity of Semisolid Redox Flow Battery Operation Principles through Mechanistic Simulations. J Phys Chem C. 2018 Oct 25;122(42):23867-77.

141. Shukla G, Franco AA. Interphases in Electroactive Suspension Systems: Where Chemistry Meets Mesoscale Physics. Batteries \& Supercaps. 2019 Jul 1;2(7):579-90.

142. Yu J, Sushko ML, Kerisit S, Rosso KM, Liu J. Kinetic Monte Carlo Study of Ambipolar Lithium Ion and Electron-Polaron Diffusion into Nanostructured TiO2. J Phys Chem Lett. 2012 Aug 2;3(15):2076-81. 